\title{
Extrasomatic Emotions
}

\author{
Emilio Tiberi \\ University of Verona
}

\begin{abstract}
I describe an investigation carried out in Italy on 54 subjects, half of whom had out-of-body experiences (OBEs) in good health, and half of whom had OBEs in a coma or in a state of presumed death. The focus of this research was the emotions subjects reported having felt during their OBEs. Results suggest that both in-the-body (somatic) and out-of-the-body (extrasomatic) emotions can be viewed on a continuum that shows them to be analogous or identical in both their nature and function. In light of recent theories of emotions, both the enhanced mental functioning and the subsequent existential changes connected with OBEs can be attributed to extraordinary positive emotions, theoretically triggered by the metaphysical perception of being during the $\mathrm{OBE}$.
\end{abstract}

Considerable research has established the validity of the so-called out-of-body experience, or OBE, as a real and objective event, albeit not quite completely explained. Surveys of OBEs have been carried out by Celia Green (1968), John Palmer (1979), Susan Blackmore (1982), Paola Giovetti (1983), and Erlendur Haraldsson (1985); Robert Monroe's book (1977) relating his journeys outside the body is well known; and Herbert Greenhouse (1975) and Scott Rogo (1978) have published books describing their laboratory experiments on OBEs.

Most of this research has reported cases of OBEs, often undertaken voluntarily, of people in excellent health. Other studies, however, have reported OBEs of people who were either clinically dead or considered so, or in a state of deep coma or cardiac arrest (Owens, Cook, and

Emilio Tiberi is Professor at the Institute of Psychology at the University of Verona. In selecting emotions and affects to be included in this study, he conducted a quantitative analysis of emotions and affects mentioned by previous near-death researchers. Requests for the results of that content analysis and for reprints of this article should be addressed to Prof. Tiberi at the Instituto di Psicologia, Facolta di Lettere e Filosofia, Università di Verona, Vicolo cieco dietro San Francesco, 37129 Verona, Italy. 
Stevenson, 1990). This type of OBE I will call the near-death out-ofbody experience, or ND OBE, after Janice Holden (1988).

I must point out that, while most OBEs do not take place within the context of other extraordinary phenomena, the ND OBE takes place inside a wider phenomenon, called by Raymond Moody (1975) the neardeath experience (NDE). However, Kenneth Ring underlined that almost every element of what he called the "core [NDE] experience" took place within the ND OBE:

[T]he feelings associated with stage I of the core experience are dependent on being out of body. They are, in fact, ... the affective concomitants of the out-of-body condition.... I will argue that the entire range of core experiences actually represents an extended out-of-body experience. $(1980$, p. 221$)$

For this reason, in the present paper I will sometimes consider the ND OBE and the NDE interchangeable.

Some authors already considered classic scholars in near-death studies have taken for granted the reality of the ND OBE. Michael Sabom (1982) reported that he found 32 subjects who had had "autoscopic" NDEs, in which they viewed their bodies as if from an out-ofbody perspective. Sabom objectively verified the out-of-body perceptions of six of those subjects, which he maintained demonstrated the reality of the ND OBE. Ring (1984) recognized the authority of Sabom's research, and wrote that his own cases confirmed it. Elsewhere, he wrote:

I believe that what happens when an individual is near the point of apparent death is a real, and not just a subjective, separation of "something"-to be specified shortly-from the physical body. . . For me, it is sufficient to postulate that a separation can take place. Just how it occurs is a problem I must leave to scientists more imaginative and daring than I. (1980, pp. 221, 233)

Melvin Morse is one imaginative and daring scientist who accepted Ring's challenge. He wrote:

I believe that by looking carefully at the work of neuroscientists one can conclude that there is within the human brain an area that is genetically coded for out-of-body experiences, tunnel experiences, and much of what we know as the near-death experience. (Morse and Perry, 1990, p. 102)

Morse and Paul Perry specifically identified an area in the right temporal lobe along the Sylvian fissure, just above the ear. Both they 
and Moody and Perry (1989) demonstrated differences between ND OBEs and autoscopic hallucinations, phenomena well known to psychiatrists.

This paper reports research I carried out in Italy in 1990 on the emotions subjects reported having had during ND OBEs and during other OBEs. There are three main theoretical approaches to the relation between emotions and other personality features and between emotions and behavior. Carroll Izard (1977) claimed that emotion serves a primarily motivational function in relation to both mental activities and behavior. Gordon Bower and P. R. Cohen (1982) and Stephen Gilligan and Bower (1984) recognized the influence of emotions on memory and on cognitive systems in general. For these reasons some authors (Izard, 1984; Zajonc, 1984; Tiberi, 1988) attributed primacy to affects over cognitive systems, whereas other authors (Lazarus, 1984; Mandler, 1975) consider cognitive systems primary. Robert Plutchik (1985) recognized the validity of these two alternative viewpoints, but wondered whether this problem of which system, emotional or cognitive, gives rise to the other isn't the same as the vicious circle of the chicken and the egg.

My position is nearer to Izard's, and through the data collected in this study I sought to verify his hypothesis. Do out-of-body emotions behave the same way as do in-the-body emotions? To what extent are the affects and emotions felt in OBEs responsible for other elements of out-of-body phenomena; or to what extent do they affect other elements? In particular, which kinds of enhanced functioning of mind and behavior do extrasomatic emotions favor, both during the $\mathrm{OBE}$ and afterwards in daily life?

The main hypothesis I intended to test was that extrasomatic or outof-the-body emotions were analogous or identical, both in nature and function, to somatic or in-the-body emotions. I am aware that the terms somatic and extrasomatic are rather reductionistic. Emotions, whether they occur while the individual is out of the body or not, are not characterized only by their relation to the body; in either case, emotions are also mental, subjective, phenomenologic, and cognitive phenomena.

With that understanding, I used the terms somatic and extrasomatic to define the two types of emotions: those taking place in a normal state of consciousness, and those taking place in the extraordinary state of consciousness when it exists by itself, outside the body. The hypothesis to be tested in this study was that these two types of emotion must be on a single continuum for the OBE to appear a natural and immanent, albeit exceptional, phenomenon. 


\section{Method}

I recruited subjects for this research through the mass media, including the major Italian newspaper Corriere della Sera and the major Italian television network RAI. I conducted this research by means of a self-report questionnaire sent to subjects and returned by mail. I derived the questionnaire from the current $\mathrm{OBE}$ and NDE literature, and grounded this work in Izard's (1977) theory of differential emotions and Kenneth Strongman's (1978) evaluation of that theory; elsewhere (Tiberi, 1988) I have justified my reasons for choosing that theory.

The questionnaire addressed eight areas: (1) the nature of the OBE, to insure that the subject really had one; (2) thoughts during the OBE; (3) memory during and after the OBE; (4) imagery during the OBE; (5) perception during the $\mathrm{OBE}$; $(6)$ drives, such as pain, sex, hunger, and thirst, during the OBE; (7) 10 differential emotions and 14 affects and their nature, function, antecedents, motivational aspect, control, and meaning in the OBE; and (8) aftereffects, including existential changes in lifestyle after the OBE.

The questions on cognitive systems and drives were included to address the interaction between emotions and personality systems (Izard, 1977), which better defines the actual nature and function of emotion. The 10 differential emotions included (1) curiosity/interest, (2) joy, (3) sadness, (4) anger, (5) fear, (6) shame, (7) surprise, (8) disgust, (9) contempt, and (10) guilt. These are Izard's (1977) 10 fundamental emotions, although other authors have proposed variable lists of basic emotions (Plutchik, 1980). The 14 affects were (1) serenity/tranquility, (2) peace, (3) relaxation, (4) love/sweetness, (5) anxiety, (6) worry/ preoccupation, (7) embarrassment, (8) boredom, (9) stress, (10) hate, (11) frustration, (12) depression, (13) crying, and (14) smiling.

I selected these differential emotions and affects not only because they have been proposed $a$ priori as primary constructs, but also because most of them have been reported as the emotions and affects experienced by subjects during OBEs. I included those not found in the OBE literature, such as disgust, contempt, hate, stress, and boredom, in order to determine whether my subjects, faced with these unusual questions, would reveal information not mentioned in previous studies.

Data from the questionnaires were tabulated, and inferences drawn from chi-squared and Fisher's exact probability tests. When chisquared tests were used, the chi-squared value is given along with the probability estimate; when the probability estimate alone is given, Fisher's exact test was used. As my subjects were self-selected recruits 
and not a randomly selected sample, my results and conclusions must be considered only suggestive. For the sake of brevity, I have generally not listed missing data and equivocal answers to each question in this report, and percentages were calculated based on those subjects who could answer each question.

\section{Results}

\section{Subjects}

I received valid questionnaires from 54 subjects. Of that number, 28 (52\%) were male and $26(48 \%)$ female. Their ages ranged from 20 to 80 years. Thirty-one subjects $(57 \%)$ were married, $12(22 \%)$ single, $9(17 \%)$ divorced or separated, and $2(4 \%)$ of undetermined marital status. Four subjects $(7 \%)$ had attended only elementary school, $34(63 \%)$ were diploma holders, $11(20 \%)$ had graduated, and $5(9 \%)$ had undetermined educational status. Twenty-nine subjects $(54 \%)$ were of the lower social class, $11(20 \%)$ middle class, $11(20 \%)$ upper class, and $3(6 \%)$ of undetermined social class. Twenty-eight subjects (52\%) lived in an urban area, $20(37 \%)$ in a rural area, $2(4 \%)$ outside the country, and $4(7 \%)$ in an undetermined residence.

\section{Description of $O B E$}

Of the 54 subjects, 27 (50\%) described OBEs occurring at the point of death, and $27(50 \%)$ described OBEs occurring, either spontaneously or voluntarily, while they were in good health.

Twenty subjects (37\%) claimed to have been out of the body once only; $33(61 \%)$ several times. The claim of multiple OBEs was less common among NDErs (50\%) than among subjects who had OBEs in other circumstances $(73 \%)$.

Only 30 subjects (56\%) claimed to have observed their bodies from a point outside the body. Twenty-four subjects (44\%) claimed to have met other people during the $\mathrm{OBE}$, while $22(41 \%)$ claimed to have met deceased people.

The number of subjects who found themselves, during the $\mathrm{OBE}$, in a world different from the everyday one was significantly greater among NDErs than among those who had OBEs in other circumstances (chisquared $=7.83, \mathrm{p}<.01$ ). 


\section{Perception During the $O B E$}

Color perception was reported as brilliant by 25 subjects ( $46 \%$ ), including 15 NDErs (56\%) and 10 who had other OBEs (37\%); as splendid by 26 subjects (48\%), including 14 NDErs (52\%) and 12 subjects who had other OBEs (44\%); as normal by 22 subjects (41\%); and as faded by 8 subjects (15\%). Though NDErs showed a tendency to report more brilliant and splendid colors than did subjects with OBEs in other circumstances, these differences approached but did not reach significance.

Seventeen subjects (31\%) reported having perceived new colors during the OBE, including 12 NDErs $(54 \%)$ and 5 who reported other OBEs $(20 \%$ ), a significant difference (chi-squared $=7.26, \mathrm{p}<.02$ ).

Twenty-nine subjects (54\%) claimed to have been able to see in the dark, including 12 NDErs $(50 \%)$ and 17 subjects with other OBEs (68\%), a statistically comparable ratio.

Eighteen subjects (33\%) reported having heard extraordinary music and $20(54 \%)$ reported normal sounds. Extraordinary music was described by 13 NDErs $(57 \%)$ but by only 5 subjects who had other OBEs $(23 \%)$; that difference bordered on significance (chi-squared $=5.36, \mathrm{p}<$ $.06)$.

\section{Drives During the $O B E$}

Only 4 subjects ( $7 \%$ ) reported having felt pain during the $\mathrm{OBE}$, which was clearly described as painless by 21 NDErs (88\%) and by 20 subjects who had other OBEs $(87 \%)$. However, while the two groups were similar in describing the OBE as painless, the 23 subjects $(43 \%)$ who reported that bodily pain ceased when the OBE began included 18 NDErs (82\%) and only 5 subjects who had OBEs in other situations $(22 \%)$, a significant difference (chi-squared $=17.0, \mathrm{p}<.0002$ ).

Six subjects $(11 \%)$ reported feeling sexual attraction during the OBE; 24 ND OBErs (92\%) and 20 other OBErs (80\%) denied sexual feelings during the OBE. Four subjects (7\%) reported having had sexual intercourse while out of the body; 23 ND OBErs (96\%) and 21 other OBErs (88\%) denied having had intercourse during the OBE. The two groups of OBErs were comparable in their reports of sexual drives and activities during the OBE.

Sensations of hunger, thirst, heat, and cold, or reports of having eaten or drunk while out of the body, were reported by between 1 and 8 
Forty subjects (74\%), including 20 in each group, differentiated their OBEs from dreams they had had; and 34 subjects (63\%), including 17 from each group, differentiated their OBEs from hallucinations they had had.

\section{Thoughts During the OBE}

Thoughts were described as clear by 44 subjects ( $82 \%$ ), and as hazy by 4 subjects (7\%). Clear thoughts were reported by 20 NDErs $(90 \%)$ and by 24 subjects who had OBEs in other circumstances (96\%), a nonsignificant difference.

Twenty-eight subjects (39\%) stated that thoughts during the OBE motivated and energized their movements. Twenty-four subjects (44\%) stated that information and learning acquired prior to the OBE were used during the OBE.

Gaining new and deep insight was mentioned more frequently by NDErs than by subjects who had other OBEs (chi-squared $=7.37, \mathrm{p}<$ $.02)$.

\section{Memory During and After the $O B E$}

Memories of what they experienced during the OBE were reported by 50 subjects (93\%), including 25 in each group. Forty-five subjects (83\%) claimed to remember all the details of the OBE, including 25 NDErs (93\%) and 20 subjects who had other OBEs (74\%), a nonsignificant difference.

\section{Imagery During the $O B E$}

Thirty-eight subjects (70\%), including 19 from each group, described images during the OBE as vivid. Thirty-two subjects (59\%) described images as shining or brilliant, including 15 NDErs (56\%) and 17 who reported other OBEs (63\%). Only 7 subjects (13\%) described images as faded; 12 NDErs $(44 \%)$ and 16 subjects with other OBEs (59\%) unequivocally denied any fading. Only 2 subjects $(4 \%)$ described images as obscure; 14 NDErs (52\%) and 16 subjects who had OBEs in other situations $(59 \%)$ clearly denied obscure images. 
subjects (between 2 and 15\%). Among ND OBErs, 24 (96\%) denied hunger and the same number denied thirst, while $23(89 \%)$ denied having eaten and the same number denied having drunk during the OBE. Among subjects who had OBEs in other circumstances, $25(100 \%)$ denied hunger and $24(96 \%)$ denied thirst, while $22(88 \%)$ denied having eaten and $20(80 \%)$ denied having drunk during the OBE. The two groups of OBErs were statistically indistinguishable in their reports of sexual, hunger, and thirst drives and activities during the OBE.

\section{Emotions and Affects During the $O B E$}

Of the 10 differential emotions studied, joy was reported by 30 subjects (56\%); curiosity by 27 (50\%); surprise by 20 (37\%); and fear by 18 (33\%). Sadness, shame, guilt, and anger were each reported by between 1 and 8 subjects (between 2 and 15\%), while no subjects mentioned disgust or contempt.

The two groups of OBErs showed comparable rates of reporting 9 of these 10 emotions; only fear was differentially reported, being described by only 5 ND OBErs (20\%) but by 13 subjects $(52 \%)$ who had other OBEs (chi-squared $=7.93, \mathrm{p}<.04$ ).

Of the 14 affects studied, serenity/tranquility was reported by 39 subjects (72\%); peace by $36(67 \%)$; relaxation by $35(65 \%)$; love by $25(46 \%)$; smiling and worry each by 20 (37\%); and anxiety by 18 (33\%). Boredom, stress, hate, depression, crying, embarrassment, and frustration were each reported by between 1 and 7 subjects (between 2 and 13\%).

A few of these pleasant affects were reported significantly more often by NDErs than by subjects who had OBEs in other circumstances: serenity/tranquility was described by 23 ND OBErs (92\%) but only 16 other OBErs $(64 \%$ ) (chi-squared $=8.85, \mathrm{p}<.03$ ); peace by 22 NDErs $(88 \%)$ but only 14 other OBErs $(56 \%)$ (chi-squared $=8.69, \mathrm{p}<.03$ ); and relaxation by 22 NDErs $(88 \%)$ but only 13 other OBErs (52\%) (chisquared $=13.77, p<.003)$. On the other hand, anxiety was described by only 5 NDErs (20\%) but by 13 other OBErs $(52 \%)$ (chi-squared $=$ $7.93, p<.04)$. Reporting rates for the other 10 affects were similar for the two groups.

Regarding the cause of emotions during the OBE, they were described as being triggered by the out-of-body environment according to 26 subjects (48\%), including 13 in each group; by people encountered during the OBE according to 19 subjects (35\%), including 10 NDErs 
and 9 other OBErs; by thoughts according to 16 subjects (30\%), including 8 in each group; and by the abandoned body by 14 subjects (26\%), again evenly divided between the two groups.

Regarding the function served by emotions during the $\mathrm{OBE}$, this was described as motivational by 19 subjects (35\%), and as adaptational by 17 subjects $(32 \%)$. Nineteen subjects $(35 \%)$ stated that emotions were the main feature of the OBE; 29 (54\%) reported that the OBE made them happy, $4(7 \%)$ reported that it made them unhappy, and $13(24 \%)$ reported that it made them sometimes happy and sometimes unhappy. Though the two groups did not differ significantly in their assessment of the function of emotions in the OBE, the ND OBErs tended to say more often that the OBE made them happy and that emotions were the most important feature of the experience.

To pursue an old controversy about whether emotions are functional or dysfunctional (Leeper, 1948), I asked subjects whether emotions during the OBE were a disturbance or a problem or whether they handicapped behavior. Seven subjects (13\%) felt emotions were a disturbance in the OBE, while $32(59 \%)$ did not; 4 subjects $(7 \%)$ felt emotions were a problem in the OBE, whereas $27(50 \%)$ did not; and 3 subjects (6\%) felt emotions handicapped behavior in the OBE, while 29 (54\%) did not. Again, while the two groups did not differ statistically, fewer ND OBErs tended to regard emotions as a disturbance (2 versus 5 other OBErs) and to regard emotions as a handicap (none versus 3 other OBErs). For the most part, the two groups agreed that emotions were adaptive, motivational, and positive.

I also tried to ascertain the role of the physical body in controlling overwhelming affects during the OBE. Fourteen subjects reported that when emotions became noxious, they went back into the body, while 16 subjects denied that; the remaining 24 subjects were perplexed by the question. Twelve subjects regarded the body as a refuge from extrasomatic emotions, while 17 subjects did not; the remaining 25 subjects could not answer this question. While differences between the two groups were not statistically significant, fewer ND OBErs reported returning to the body when emotions became noxious (5 versus 9 other OBErs) and regarded the body as a refuge from extrasomatic emotions ( 3 versus 9 other OBErs).

Finally, I tried to inquire about the emotions of other people the subjects had met during the OBE. Many subjects did not know how to answer such questions, and gave very uncertain answers. Nevertheless, the two groups agreed in reporting only happy and self-assured people in the OBE, and having met no sad people. 


\section{Existential Changes After the $O B E$}

Certainty of survival after death was reported by 34 subjects $(63 \%)$, as was a belief that death does not interrupt life. While differences between the two groups were not statistically significant, more ND OBErs endorsed both these attitudes (for certainty of survival, 20 versus 14 other $O B E r s$, and for life uninterrupted by death, 21 versus 13 other OBErs).

In regard to new views of life, $31(57 \%)$ believed that a better appreciation of death had given them a better appreciation of life; 36 subjects $(67 \%)$ reported that they felt more detached, serene, and peaceful about life events after the OBE; 20 subjects (37\%) reported they felt more like a "pilgrim" on earth, seeing everything in the light of an afterlife; 26 subjects (48\%) felt less engaged in business; 27 subjects $(50 \%)$ reported a decreased interest in wealth; 31 subjects $(57 \%)$ reported being able to perform their jobs with a more serene and detached disposition; and only 4 subjects $(7 \%)$ reported they now preferred their lives to be shortened. While NDErs tended to give more positive responses to these questions, those differences never reached statistical significance.

In regard to morality and interpersonal relationships, 27 subjects (50\%) felt like being more observant and more moral after the OBE; 29 subjects (54\%) described their relationships with others as more peaceful and harmonious; 24 subjects (44\%) claimed to have become more tolerant, amiable, and understanding; and 28 subjects ( $52 \%$ ) claimed to have become more attached to their families. The two groups were statistically comparable in reporting these aftereffects.

In regard to mood, 23 subjects (43\%) reported being happy regardless of circumstances now; only 10 subjects (19\%) reported getting as bored as they had before the OBE, while 33 subjects $(61 \%)$ claimed they did not get as bored as they used to; 17 subjects ( $32 \%)$ felt they were just as afraid of pain as they had been before the OBE; and 33 subjects $(61 \%)$ believed they were better off than people who had not had OBEs, because of their new knowledge, self-assurance, and happiness. Nineteen (70\%) of the NDErs believed that reaching the threshold of death in their OBEs was an extremely positive experience.

In regard to religious and philosophical beliefs, 25 subjects $(46 \%)$ became more interested in religious beliefs after their OBEs; 22 subjects (41\%) felt religious beliefs had been strengthened or verified by their OBEs; 31 subjects (57\%) claimed their OBE had affected their philosophical conceptions of life; and 38 subjects (70\%) became more interested in knowledge and science after their OBEs. The two groups 
were statistically indistinguishable in reporting these changes. Thirty subjects $(57 \%)$ felt wiser, more mature, and more balanced since the OBE, including 17 NDErs (71\%) and 13 other OBErs (57\%). This difference was significant, with NDErs reporting a greater sense of wisdom, maturity, and balance and fewer "can't answer" responses (chi-squared $=10.48, \mathrm{p}<.005$ ).

In regard to health, 2 subjects (4\%) described their health as worsened since the OBE, while 42 subjects (78\%) denied a decline in health; 1 subject (not an NDEr) acknowledged suffering from physical illnesses since the OBE, while 46 subjects (85\%) denied subsequent illness; and 4 subjects $(7 \%)$ reported feeling more unbalanced and conflictual, while 39 subjects $(72 \%)$ denied those feelings. These few subjects who acknowledged health problems subsequent to their OBEs were evenly distributed between the two groups.

\section{Influence of Emotions and Affects on Thoughts in the $O B E$}

Subjects who experienced positive emotions and affects were more likely to claim that they grasped new and deeper insight during the $\mathrm{OBE}$ than were those who did not report positive emotions and affects. This was true for the emotion of joy (chi-squared $=4.90, \mathrm{p}<.02$ ) and approached significance for curiosity (chi-squared $=3.28, \mathrm{p}<.06$ ); and it was true for the affects of serenity (chi-squared $=9.11, p<.002$ ), peace (chi-squared $=7.35, \mathrm{p}<.006$ ), relaxation (chi-squared $=4.56, \mathrm{p}$ $<.03$ ), and love (chi-squared $=3.38, \mathrm{p}<.04$ ). On the other hand, subjects who experienced anxiety were also more likely to report new insight during the NDE than those who did not experience anxiety (chi-squared $=5.41, \mathrm{p}<.02$ ).

Subjects who experienced positive emotions and affects were also more likely to feel that thoughts during the OBE were useful to explore than were subjects who did not report positive emotions and affects. This was true for the emotions of joy (chi-squared $=4.42, p<$ .03 ) and curiosity (chi-squared $=4.74, p<.02$ ), and for the affects of serenity (chi-squared $=4.17, \mathrm{p}<.04)$, peace $($ chi-squared $=4.73, \mathrm{p}<$ .02 ), and relaxation (chi-squared $=5.10, \mathrm{p}<.02$ ).

The conviction that thoughts during the OBE provided energy and motivation in moving about was more often reported by those who experienced curiosity than by those who didn't (chi-squared $=\mathbf{5 . 5 4}, \mathrm{p}$ $<.01$ ), and marginally less often reported by those who experienced worry than by those who didn't (chi-squared $=3.44, p<.06$ ). NDErs and other OBErs differed in what emotions had this effect. Among 
NDErs, this conviction was more prevalent among those who felt fear $(p<.05)$, while among other OBErs, it was more prevalent among those who experienced joy $(p<.01)$, peace $(p<.01)$, and relaxation $(p$ $<.03$ ).

Thoughts guiding movements while out of the body were reported more often by those who had feelings of curiosity than by those who didn't (chi-squared $=8.92, \mathrm{p}<.002$ ). Among NDErs, this effect was associated with the emotion of fear $(p<.004)$, while among other OBErs it was associated with joy $(p<.02)$ and serenity $(p<.03)$. The ability to move about just by thinking about it was also reported more often by those who felt curiosity (chi-squared $=3.77, p<.05$ ); again, among non ND OBErs this experience was associated with joy ( $p<$ $.01)$.

The ability to read other people's minds was reported less often by those who felt worry (chi-squared $=5.59, \mathrm{p}<.01$ ). Thoughts were described as hazy more often by those who felt worry (chi-squared $=$ $3.70, \mathrm{p}<.05$ ) and fear (chi-squared $=4.70, \mathrm{p}<.03$ ).

\section{Influence of Emotions and Affects on Memory and Imagery}

Positive emotions and affects also seem to enhance memory and imagery. Serenity tended to prevent forgetting the OBE (chi-squared = $3.88, \mathrm{p}<.04$ ), and to enhance imagery of other dimensions (chisquared $=9.47, \mathrm{p}<.002$ ), as did joy (chi-squared $=5.41, \mathrm{p}<.02$ ), peace (chi-squared $=6.12, \mathrm{p}<.01$ ), and relaxation (chi-squared $=4.38$, $\mathrm{p}<.03$ ). Feeling love was associated with neatness of images perceived in the OBE (chi-squared $=4.83, \mathrm{p}<.02$ ).

\section{Influence of Emotions and Affects on Perception}

Subjects who experienced positive emotions and affects tended also to perceive new colors in the OBE. This was true for the emotion of joy (chi-squared $=4.50, \mathrm{p}<.03$ ) and the affects of serenity (chi-squared $=$ $5.23, \mathrm{p}<.02$ ), peace (chi-squared $=5.28, \mathrm{p}<.02$ ), love (chi-squared $=$ $4.80, \mathrm{p}<.02$ ), and relaxation (chi-squared $=10.80, \mathrm{p}<.001$ ). Conversely, new colors tended not to be perceived by those who felt anxiety in the OBE (chi-squared $=3.97, \mathrm{p}<.04$ ). The usual colors, on the other hand, tended not to be reported by those who felt serenity (chi-squared $=3.75, \mathrm{p}<.05)$, peace (chi-squared $=3.60, \mathrm{p}<.05)$, love (chi-squared $=5.49, \mathrm{p}<.01$ ), and absence of anxiety (chi-squared $=4.59, \mathrm{p}<.03$ ).

Seeing brilliant colors was also associated with the positive affects of 
serenity (chi-squared $=7.01, \mathrm{p}<.008$ ), peace (chi-squared $=4.77, \mathrm{p}<$ .02 ), love (chi-squared $=13.00, \mathrm{p}<.0003$ ), and smiling (chi-squared $=$ $4.61, \mathrm{p}<.03$ ). Likewise, seeing splendid colors was associated with serenity (chi-squared $=5.48, \mathrm{p}<.01$ ), relaxation (chi-squared $=4.26, \mathrm{p}$ $<.03$ ), love (chi-squared $=4.18, \mathrm{p}<.04$ ), and with the absence of anxiety (chi-squared $=4.26, \mathrm{p}<.03$ ) or worry (chi-squared $=4.18, \mathrm{p}<$ $.04)$. On the other hand, seeing normal colors tended not to be reported by those who felt joy (chi-squared $=3.72, \mathrm{p}<.05$ ), serenity (chisquared $=4.87, \mathrm{p}<.02$ ), peace (chi-squared $=6.23$, $\mathrm{p}<.01$ ), and relaxation (chi-squared $=6.10, \mathrm{p}<.01$ ). The ability to see in the dark during the OBE was significantly associated only with the emotion of curiosity (chi-squared $=3.52, \mathrm{p}<.05$ ).

Hearing extraordinary music was also associated with the positive emotion of joy (chi-squared $=5.97, p<.01$ ) and the positive affects of serenity (chi-squared $=4.41, \mathrm{p}<.03)$, peace $($ chi-squared $=6.36, \mathrm{p}<$ .01 ), and relaxation (chi-squared $=4.60, \mathrm{p}<.03$ ).

\section{Influence of Emotions on Other Emotions in the $O B E$}

Those who experienced fear during the OBE were more likely to agree that extrasomatic emotions are helpful in motivating, guiding, or energizing behavior (chi-squared $=4.43, \mathrm{p}<.03$ ), that extrasomatic emotions help in adapting to new situations (chi-squared $=4.90, \mathrm{p}<$ .02 ), that extrasomatic emotions sustain the mind in reaching goals (chi-squared $=3.75, \mathrm{p}<.05$ ), and that extrasomatic emotions make people unhappy (chi-squared $=3.66, \mathrm{p}<.05$ ).

On the other hand, those who experienced serenity were more likely to agree that extrasomatic emotions make people happy (chi-squared $=$ $3.64, \mathrm{p}<.05$ ). Extrasomatic emotions were regarded as a problem less often by those who experienced joy (chi-squared $=4.94, \mathrm{p}<.02$ ), peace (chi-squared $=5.11, \mathrm{p}<.02$ ), and absence of fear (chi-squared $=5.77, \mathrm{p}$ $<.01)$. Similarly, extrasomatic emotions were regarded as a disturbance less often by those who experienced joy (chi-squared $=15.89, \mathrm{p}$ $<.0001$ ), serenity (chi-squared $=5.32, \mathrm{p}<.02$ ), and peace (chi-squared $=6.09, \mathrm{p}<.01$ ); and extrasomatic emotions were regarded as a handicap less often by those who experienced serenity (chi-squared $=$ $5.92, \mathrm{p}<.01$ ) and peace (chi-squared $=3.87, \mathrm{p}<.04$ ).

Retreating back into the body when extrasomatic emotions became noxious or too intense was reported more often by those who experienced fear (chi-squared $=9.04, p<.002$ ). Regarding the body as a refuge from extrasomatic emotions was also reported more often by those who felt fear (chi-squared $=5.54, \mathrm{p}<.01$ ), but less often by those 
who experienced joy (chi-squared $=3.69, \mathrm{p}<.05$ ) and peace (chisquared $=4.25, \mathrm{p}<.03$ ).

The assertion that emotions and affects are the most important feature of OBEs was significantly associated only with the affect of love (chi-squared $=3.75, \mathrm{p}<.01$ ).

Finally, cessation of pain that existed prior to the OBE was associated with a feeling of peace (chi-squared $=3.85, \mathrm{p}<.04$ ). In ND OBEs, pain during the experience was associated with fear (chisquared $=4.77, p<.02$ ). Every NDEr who denied feeling fear also denied feeling pain, and only one NDEr who felt peace and joy reported feeling pain during the experience.

\section{Influence of Emotions and Affects on Aftereffects}

Subjects who did not feel fear during the OBE were more likely than those who did to report subsequently that their greater appreciation for death gave them a greater appreciation for life (chi-squared $=4.01$, $\mathrm{p}<.04$ ), and that they no longer feared pain (chi-squared $=4.28, \mathrm{p}<$ $.03)$.

The OBE was regarded as a privilege that gives experiencers an advantage because of their consequent new knowledge, self-assurance, and happiness more often by those who felt joy (chi-squared $=3.99, p$ $<.04)$, serenity (chi-squared $=4.50, \mathrm{p}<.03$ ), peace (chi-squared $=$ $5.05, \mathrm{p}<.02$ ), and relaxation (chi-squared $=3.97, \mathrm{p}<.04$ ).

Subjects who felt relaxed during the OBE were more likely than others to feel detachment, serenity, and peace afterward (chi-squared $=4.33, \mathrm{p}<.03$ ), to be able to perform their jobs in serenity and detachment (chi-squared $=4.20, \mathrm{p}<.04$ ), and to feel less bored than they had before the OBE (chi-squared $=3.84, \mathrm{p}<.04$ ).

Subjects who experienced love during the OBE were more likely than others to espouse and observe moral principles afterward (chi-squared $=4.83, \mathrm{p}<.02$ ), to feel stronger attachment to family (chi-squared $=$ $4.28, \mathrm{p}<.03$ ), and to have increased interest in religious beliefs (chisquared $=4.22, \mathrm{p}<.03$ ).

\section{Discussion}

The finding that repeated OBEs were less common among NDErs than among those who had OBEs in other circumstances was expected, as some of the latter were voluntarily induced. 
NDErs and other OBErs gave similar descriptions of viewing their bodies from an extrasomatic perspective, of meeting other people while out of the body, and of being able to differentiate their OBEs from dreams and hallucinations; but NDErs reported having gone to a nonordinary dimension of existence more often than did other OBErs.

The two groups gave statistically comparable descriptions of thoughts during the OBE, though NDErs reported gaining new deep insight more often than did other OBErs. Likewise, the two groups described their out-of-body memory, imagery, and perceptions in similar terms, although NDErs reported brilliant colors, new colors, and extraordinary music more often than did other OBErs. Both groups described the OBE as essentially painless; the greater proportion of NDErs than other OBErs who described a cessation of bodily pain was expected, as many NDErs entered the OBE while in pain while the other OBErs were in good health and primarily free of pain prior to the $\mathrm{OBE}$.

Bodily drives, including sexual attraction, hunger, thirst, heat, and cold, and associated activities were extremely rare among both groups of OBErs, though not entirely absent, supporting Monroe's report (1977) that some individuals do describe eating, drinking, and sexual intercourse while out of the body.

The two groups described comparable frequencies of pleasant emotions, but fear was less common in NDEs than in OBEs occurring under other circumstances. NDErs reported pleasant affects more often than did other OBErs, while other OBErs reported more anxiety than did NDErs. However, unpleasant emotions and affects were generally rare among both groups.

The two groups agreed on the precipitants and functions of extrasomatic emotions, although NDErs were more likely to say that emotions were the most important part of the experience and that the experience made them happy, while other OBErs were more likely to describe extrasomatic emotions as a disturbance or handicap. In general both groups regarded emotions in the OBE as adaptive, motivational, positive, and controllable by will; this contradicts Rogo's finding (1978) that extrasomatic emotions may be overwhelming.

While few significant differences emerged between the two groups in terms of emotions and affects, NDErs seemed to be more detached from their bodies, as though they felt their emotional centers were no longer inside the body and that a point of no return to the body was near.

Both groups claimed to have made numerous and remarkable psychological and behavioral changes following their OBEs. Differences between the two groups in aftereffects were seldom significant, but there was a persistent tendency for NDErs to emphasize more positive and powerful effects than did other OBErs. 
Neither group acknowledged significant physical or emotional problems subsequent to the OBE. These data present a more optimistic picture than did Moody and Perry (1989), who reported that many NDErs experience difficulty and need psychiatric support in readapting to their environment after the profound changes precipitated by their experiences.

Both groups reported enjoying life more than before the OBE, and being less afraid of death but not of pain. Likewise, both groups reported increased interest since the $\mathrm{OBE}$ in religion, philosophy, and science. Ring (1984) described a heightened enthusiasm for knowledge as a characteristic aftereffect of the NDE; these data suggest that any OBE even in the absence of proximity to death can stimulate this tendency.

In fact, many of the behavioral changes often described as consequences of an NDE (Lorimer, 1990; Moody, 1975; Moody and Perry, 1989; Noyes, 1982; Ring, 1980, 1984; Sabom, 1982) may be attributable to the out-of-body experience, which leads the individual to believe that he or she is coming into contact with metaphysical realities. Subjects in this study who were in excellent health at the time of their OBEs and underwent those experiences voluntarily reported existential changes similar to those of the NDErs. NDErs do tend to report these changes with greater frequency and to regard them as more profound than do other OBErs. I suggest, however, that these differences between NDEs and OBEs occurring under other circumstances can be explained by contagion within the NDEr's mind between effects attributable to the OBE and those possibly attributable to other features of the NDE.

In regard to the effect of emotions and affects on thought, positive emotions and affects seemed conducive to insight during the OBE. The finding that anxiety was also associated with new insight may be attributed to the close association of the affect of anxiety with the emotion of curiosity (Izard, 1977). Positive emotions and affects seemed also to enhance memory, imagery, and perception during the OBE; curiosity seemed a particular potent factor.

The theory of differential emotions maintains that emotion interacts with all six personality systems, one of which is emotion itself. Thus an emotion may contribute to the amplification or diminution of another emotional arousal, or to the evaluation of its function (Izard, 1977). In this sample there were complex effects both of positive emotions and affects and of fear on the experience and appreciation of other emotions.

In regard to the influence of emotions and affects on the aftereffects 
of the OBE, the data showed a consistent pattern. Again and again the positive emotions and affects such as joy, serenity, peace, relaxation, and love were repeatedly associated with aftereffects related to belief in survival, attitude toward death, a new appreciation for life, enhanced moral commitment, interpersonal relationships, moods, states of mind, religious beliefs, philosophical ideas, and physical and mental health. This pattern was most pronounced following ND OBEs, while for OBEs occurring in other circumstances these effects were associated primarily with serenity and peace and occasionally with the absence of fear.

Thus the changes following an OBE are mainly attributed to a few emotions and affects, especially feelings of serenity, peace, and relaxation, elements that were more commonly experienced in NDEs than in OBEs occurring under other circumstances. On the one hand, these data confirm the findings of previous studies, while on the other they suggest a new field of investigation: the role of extrasomatic emotions on other elements of the OBE and its aftereffects.

Previous researchers' findings supported by these data include corroboration of the basic phenomena experienced in OBEs; the dichotomization of OBEs into those related to a near-death crisis and those occurring in a state of health, including those voluntarily induced; and enhancement of mental functions, both cognitive and affective, even in the face of impaired brain physiology in ND OBEs. Furthermore, this study corroborated claims of mental and behavioral changes following OBEs, attributable, according to the subjects, to experiences outside the body. The agreement between the data presented here and those collected by previous authors supports the validity of these changes and lends credence to my investigation of the association between these changes and extrasomatic emotions.

The consistent correlation of enhanced mental functions in OBEs to the experience of positive emotions and affects leads me to attribute these effects to extrasomatic emotions, although I am aware that correlation does not necessarily imply causality. Similar conclusions could be drawn about internal existential and behavior aftereffects of OBEs: they are consistently correlated to the same positive emotions and affects, and can therefore be attributed to them. The same cannot be said about unpleasant emotions such as fear, which yielded no consistent pattern of associations across ND OBEs and other OBEs. These associations do not seem causal, as they may be attributed to correlations of fear and aftereffects with different intervening variables in different circumstances.

The presence of negative emotions, especially fear and anxiety, indi- 
cates that risks and dangers are perceived in the out-of-body realm, perhaps because subjects are aware of having reached a dimension that seems unnatural and inexplicable at the time. A woman interviewed by Paola Giovetti reported experiencing fear in her OBE "because what was happening to me was so unexplainable that it frightened me very much" (1983, p. 62). David Lorimer (1990) explained the presence of negative emotions in ND OBEs as conflictual hesitations of the subjects, who seek to return to their bodies to escape the "cosmic discord" they feel in the out-of-body condition. Sabom (1982) reported a man who felt sad in his NDE because he could see his wife crying, and a woman who felt extrasomatic anxiety, fear, anger, and fright at the thought of her physical body being abandoned and perhaps endangered.

We tend spontaneously to attribute aftereffects of the OBE directly to the metaphysical perception of existence. But such an attribution is only partly correct, as it ignores the influence of emotion on the metaphysical perception of existence. These data suggest that a more accurate attribution is that the metaphysical perception indirectly and its emotional evaluation directly give rise to a motivational need eventually expressed as behavioral change. In other words, the motivational explanation connecting the stimulus situation to the aftereffect is inadequate without considering its mediation through the emotional circuit. All radical changes require hard internal sacrifice that can be nourished and sustained only by exceptional affective impulses, which are both motivating and rewarding. Thus considering the natural role of emotion in change we can understand the connection between extrasomatic emotions and the extraordinary aftereffects of OBEs. The object of this study was to explore the relation of aftereffects to motivation and emotional gratification; but beyond the purposes of this study, the extraordinary power of out-of-body emotions signals the objective reality of the OBE, as no mere dream could stimulate such radical and lasting changes.

These data seem to confirm the primary working hypothesis of this study, that extrasomatic or out-of-body emotions are similar in nature and function to emotions experienced in the body. Starting with the nature of emotions, subjects used the same words to describe both somatic and extrasomatic emotions, implying that labels such as fear, joy, anger, peace, love, and serenity, borrowed from bodily experience, also apply to out-of-body experience.

Some authors (Izard, 1977) use these labels to refer to complete emotions, as contrasted to their component levels of emotion, such as the neurophysiological-electrochemical level, the neuromuscular- 
motoric level, and the phenomenological-consciousness level. Other authors (Plutchik, 1980) use these labels to denote a complete chain of events, including the antecedents, the three component levels implied by Izard, the motivational urge, and the subsequent behavioral realization that restores homeostatic status to the body.

It is likely, however, that subjects reporting extrasomatic emotions use these labels in the sense of popular language rather than the scientific definition. "Fear" might mean to them simply the subjective feeling, its phenomenological or consciousness level. The subjects I interviewed never mentioned the physiological aspects of their emotions or their facial expression, although future studies might perhaps ask specifically about different levels of emotion. Charles Tart's researches $(1967,1968)$ on electroencephalographic alphoid activity during OBEs represented a pioneering attempt but did not yield any relevant information about emotional components.

On the other hand, the questionnaire I used asked explicit questions about antecedents, but subjects' responses were few and insufficient. The general trend of my interviewees' answers was to locate the antecedents of emotions in the out-of-body environment. Their awareness of existing outside the body in a metaphysical dimension of being, which was generally an amiable environment, stimulated the extraordinary emotions and affects, almost all of which were pleasant. Some authors (Giovetti, 1989; Lorimer, 1990) compared this metaphysical existence during the OBE to that experienced by mystics. Furthermore, the awareness that the intensity of extrasomatic emotion exceeds anything previously experienced becomes itself an antecedent for more extraordinary emotions, thus starting a circular reaction.

In regard to the functions of extrasomatic emotions, these data generally support a motivational influence on out-of-body phenomena and aftereffects, as predicted by many theories of somatic emotions. Extrasomatic emotions also seem to serve informative and representative, or evaluative, functions (Cichetti and Hesse, 1982; Dahl, 1979; Leventhal, 1982; Scherer, 1982, 1983). In fact, starting with extrasomatic emotions and affects, which together with the aftereffects are the most salient aspects of the $\mathrm{OBE}$, it is possible to construct an adequate representation of the major phenomena of metaphysical experience. That is, the emotions and affects not only provide information about the $\mathrm{OBE}$, but also give it a very positive and stimulating quality beyond words (Ring, 1980); the tremendous emotional reaction of OBErs as they relate their metaphysical experiences allows the listener to imagine the phenomenon to some extent, but not to obtain a representative image of it, which remains ineffable. 
The study of extrasomatic emotions raises the question of how emotions can exist independently of the body, or more generally, how mind can exist with all its affective and cognitive functions outside the body, how consciousness and self can exist independently of the brain. The current answer of neuroscience and psychology is that no affective or cognitive mental operation is possible without the mediation of the brain and its complex neurochemical and physiological interactions. In other words, these sciences deny the possibility of consciousness without the body.

Nevertheless, the OBE is without doubt an objective fact. We cannot close our eyes to the evidence just because we cannot explain it. Fortunately, a breach seems to have opened even among scientists. Sabom (1982) quoted neurophysiologist Charles Sherrington as saying

That our being should consist of two fundamental elements [mind and brain] offers, I suppose, no greater inherent improbability than that it should rest on one only [brain]. (Sabom, 1982, p. 181)

He further quoted neurosurgeon Wilder Penfield as saying

For myself, after a professional lifetime spent in trying to discover how the brain accounts for the mind, it comes as a surprise now to discover, during this final examination of the evidence, that the dualist hypothesis [separation of mind and brain] seems the more reasonable of the two possible explanations. (Sabom, 1982, p. 183)

As for Sabom himself, he wrote that he could find some clues to the independence of the mind from the body in the ability of the mind voluntarily to control the highest functions of the human brain, as when subjects through biofeedback can control their own blood pressure, temperature, pain threshold, and even brainwave characteristics.

The mystery remains. One day neuroscience may be able to reconcile these two positions; irreconcilable as they now seem, they are not necessarily contradictory. It is not contradictory to imagine that the neurochemical and physiological mediation of the brain is necessary for the mind (or self), already existing independently of the brain, to act through the body on the physical world. That is, brain mediating mind does not necessarily imply brain causing or giving rise to mind.

This study tested and found data supporting the hypothesis that outof-body emotions are similar to bodily emotions in nature and function. Why was that hypothesis so important that it was given a central place around which this study was organized? The answer lies in the impor- 
tance of demonstrating continuity between the two kinds of emotion, and therefore by implication between the two kinds of experience, bodily and out-of-body, and between the two worlds.

Continuity and oneness of existence explain all the extraordinary phenomena of the OBE as well as the positive nuances of the NDE. While the two worlds participate in the same existence, the NDE implies a deeper participation on the ontological continuum connecting the two worlds. That explains the greater enhancement of mental (and emotional) functions in ND OBEs as compared to other OBEs. But this ontological explanation involves metaphysics. Perhaps it is time to remove the prefix "para-" from that branch of psychology. The world of human experience is wider than that of current experimental science, and psychology may have to return to its philosophical roots in order to provide ultimate explanations of phenomena.

\section{References}

Blackmore, S.J. (1982). Beyond the body: An investigation of out-of-the-body experiences. London, England: Heinemann.

Bower, G.H., and Cohen, P.R. (1982). Emotional influences in memory and thinking: Data and theory. In Clark, M., and Fiske, S. (Eds.), Affect and cognition. Hillsdale, NJ: Lawrence Erlbaum.

Cichetti, D., and Hesse, P. (1982). Perspectives on an integrated theory of emotional development. New Directions in Child Development, 16, 3-48.

Dahl, H. (1979). The appetite hypothesis of emotion: A new psychoanalytic model of motivation. In Izard, C. (Ed.), Emotions in personality and psychopathology (pp. 201225). New York, NY: Plenum.

Gilligan, S.G., and Bower, G.H. (1984). Cognitive consequences of emotional arousal. In Izard, C.E., Kagan, J., and Zajonc, R.B. (Eds.), Emotion, cognition, and behavior (pp. 547-588). New York, NY: Academic Press.

Giovetti, P. (1983). Viaggi senza corpo [Journeys without the body]. Milan, Italy: Armenia.

Giovetti, P. (1989). Viaggi dell'anima [Journeys of the spirit]. Milan, Italy: Armenia.

Green, C.E. (1968). Out-of-the-body experiences. London, England: Hamish Hamilton.

Greenhouse, H.B. (1975). The astral journey. Garden City, NY: Doubleday.

Haraldsson, E. (1985). Representative national surveys of psychic phenomena: Iceland, Great Britain, Sweden, USA and Gallup's multinational survey. Journal of the Society for Psychical Research, 53, 145-158.

Holden, J.M. (1988). Rationale and considerations for proposed near-death research in the hospital setting. Journal of Near-Death Studies, 7, 19-31.

Izard, C.E. (1977). Human emotions. New York, NY: Plenum.

Izard, C.E. (1984). The primacy of emotions in emotion-cognition relationships and human development. In Izard, C.E., Kagan, J., and Zajonc, R. (Eds.), Emotion, cognition, and behavior. New York, NY: Academic Press.

Lazarus, R.S. (1984). On the primacy of cognition. American Psychologist, 39, 124-129.

Leeper, R.W. (1948). A motivational theory of emotion to replace "emotion as disorganized response." Psychological Review, 55, 5-21.

Leventhal, H. (1982). The integration of emotion and cognition: $A$ view from the 
perceptual-motor theory of emotion. In Clark, M.S., and Fiske, S.T. (Eds.), Affect and cognition. Hillsdale, NY: Erlbaum.

Lorimer, D. (1990). Whole in one: The near-death experience and the ethic of interconnectedness. London, England: Arkana.

Mandler, G. (1975). Mind and emotion. Chichester, NY: John Wiley.

Monroe, R.A. (1977). Journeys out of the body. New York, NY: Anchor Doubleday.

Moody, R.A., Jr. (1975). Life after life. Covington, GA: Mockingbird Books.

Moody, R.A., Jr., and Perry, P. (1989). The light beyond. New York, NY: Bantam.

Morse, M.L., and Perry, P. (1990). Closer to the light: Learning from the near-death experiences of children. New York, NY: Villard.

Noyes, R., Jr. (1982). The human experience of death or, what can we learn from neardeath experiences? Omega, 13, 251-259.

Owens, J.E., Cook, E.W., and Stevenson, I. (1990). Features of "near-death experience" in relation to whether or not patients were near death. Lancet, 336, 1175-1177.

Palmer, J. (1979). A community mail survey of psychic experiences. Journal of the American Society for Psychical Research, 73, 221-251.

Plutchik, R. (1980). A general psychoevolutionary theory of emotion. In R. Plutchik and H. Kellerman (Eds.), Emotion: Theory, research, and experience. Vol. 1. Theories of emotion (pp. 3-33). New York, NY: Academic Press.

Plutchik, R. (1985). On emotion: The chicken-and-egg problem revisited. Motivation and Emotion, 9, 197-200.

Ring, K. (1980). Life at death: A scientific investigation of the near-death experience. New York, NY: Coward, McCann and Geoghegan.

Ring, K. (1984). Heading toward omega: In search of the meaning of the near-death experience. New York, NY: William Morrow.

Rogo, D.S. (1978). Mind beyond the body. New York, NY: Penguin Books.

Sabom, M.B. (1982). Recollections of death: A medical investigation. New York, NY: Harper and Row.

Scherer, K.R. (1982). Emotion as a process: Function, origin and regulation. Social Science Information, 21, 555-570.

Scherer, K.R. (1983). La comunicazione non verbale delle emozioni [Non Verbal communication of emotions]. In Attili, G., and Ricci Bitti, P.E. (Eds.), Comunicare senza parole. Rome, Italy: Bulzoni.

Strongman, K.T. (1978). The psychology of emotion. New York, NY: John Wiley.

Tart. C. (1967). A second psychophysiological study of out-of-the-body experiences in a gifted subject. International Journal of Parapsychology, 9, 251-258.

Tart. C. (1968). A psychophysiological study of out-of-the-body experiences in a gifted subject. Journal of the American Society for Psychical Research, 62, 3-27.

Tiberi, E. (1988). Il primato delle emozioni [The primacy of emotions]. Milan, Italy: Giuffrè.

Zajonc, R.B. (1984). On the primacy of affect. American Psychologist, 39, 117-123. 